\title{
ASSOCIAÇÃO DE DOENÇA DE WILSON E SINDROME EXTRAPIRAMIDAL NÃO WILSONIANA NA MESMA FAMILIA
}

\author{
EGBERTO R. BARBOSA - URSULA P. KOSTOW - ROBERTO HIRSCH \\ EDUARDO R. CANGADO - M. SCAFF - HORACIO M. CANELAS
}

\begin{abstract}
RESUMO - Distúrbios do movimento, geralmente de tipo distóníco, têm sido relatados em heterozigotos para doença de Wilson (DW). O presente relato assinala a presença em uma mesma família de heterozigoto para DW com quadro distônico e sua sobrinha com quadro clássico de DW. Discutem-se as peculiaridades dessa familla, comparando-se aos dados da literatura, bem como os possíveis mecanismos etiopatrogênicos envolvidos.
\end{abstract}

Wilson's disease and non wilsonian extrapyramidal syndrome in the same family.

SUMMARY - Movement disorders, mostly dystonia, sometimes occur in heterozygotes for Wilson's disease (WD). A patient with metabolic abnormalities suggestive of heterozigose for WD and dystonia is reported. His niece showed the typical neurological and metabolic abnormalities of WD. This rare coincidence and the etiopathogenic mechanisms involved are discussed.

Distúrbios do movimento, geralmente expressados por quadro distônico, tem sido relatados em pacientes com anormalidades metabólicas sugestivas de heterozigose para a doença de Wilson (DW) ${ }^{2-4,7}$. Em alguns desses relatos há história familiar de DW.

A familia a ser apresentada constitui mais um exemplo dessa situação rara, porém de grande interesse para a compreensão dos fenômenos decorrentes dos distúrbios do metabolismo do cobre.

\section{OBSERVAÇŌES}

Caso 1 - OB (Reg HC 7010874-B), 54 anos, masculino, branco, desenhista, procedente de São Paulo, SP. Paciente assintomático até os 38 anos de idade, quando começou a apresentar movimentos involuntários lentos em território distal do membro superior direito (MSD), dificultando a escrita $€$ a atividade profissional. Esses distúrbios motores evoluiram lentamente, acometendo o território proximal de MSD e, após 10 anos, a região cervical, com lateralizaçăo do segmento cefálico para a direita (D). Há um ano, vem apresentando dificuldade para a abertura ocular bilateralmente. Antecedentes familiares: sobrinha (DM) com doença de Wilson comprovada, conforme descrição a seguir. Năo há consangüinidade na familia. Ao exame neurológico apresenta movimentos distônicos acometendo face (blefarospasmo e distonia oromandibular), segmento cervical (com laterocolo para a $D$ ) e todo o MSD (com posturas distônicas nesse membro). Não há outras alteraçōes ao exame neurológico e a avaliação neuropsicológica não revela anormalidades. A pesquisa do anel de Kayser-Fleischer mostrou-se negativa. Exames complementares - Líqüido cefalorraqueano

Divisão de Clínica Neurológica do Hospital das Clínicas da Faculdade de Medicina da Universidade de São Paulo.

Dr. Egberto R. Barbosa - Clinica Neurologica, Hospital das Clínicas - Caixa P0stal 8096 01051 Säo Paulo SP - Brasil. 
e eletrencefalograma normais; ceruloplesmina $20.7 \mathrm{U} / \mathrm{L}$ (normal 23,3-33,9); cobre sérico 116 u/dL (normal 65-150); cobre urináric $139 \mathrm{u} / 24 \mathrm{~h}$ (normal: menor que 150); dosagem de cobre em tecido hepático $163 \mathrm{ug} / \mathrm{g}$ de peso seco (normal: menor que 50); exame histológico de figado: processo inflamatório crônico granulomatoso, com pesquisa de bacilos álcool-ácido resistentes e fungos negativa; enzimas hepáticas normais. Tomografia de crânio (TC): moderada dilatação dos ventrículos laterais, com sulcos e cisternas discretamente alargados; imagens de ressonåncia magnética sem outras anormalidades além daquelas presentes na tomografia de crânio. O quadro distônico está satisfatoriamente controlado com biperideno $(8 \mathrm{mg} / \mathrm{dia})$ e diazepam $(20 \mathrm{mg} / \mathrm{dia})$.

Caso 2 - DM (Reg HC 2471999-B), 17 anos, feminina, branca, estudance, procedente de São Paulo, SP. Há um ano, aparecimento de movimentos involuntários arrítmicos, distalmente nos membros superiores e na face, associados a tremor do MSD. Esses movimentos anormais instalaram-se de modo insidioso e progressivo, levando a acentuada dificuldade à escrita. Alguns meses após, surgiu diffculdade à fala e retração de lábio superior. Ao exame físico geral, não apresentava anormalidades. O exame oftalmológico com lâmpada de fenda revelou anel de Kayser-Fleischer em ambos os olhos. $O$ exame neurológico mostrou movimentos coréicos acometendo membros e face; tremor do tipo postural, grosseiro, às vezes assumindo caráter de «bater de asas» em MSD; disartria de tipo distônico e riso sardônico. Exames complementares - Ceruloplasmina 5,2 U/L (normal: 21,3-42,1); cobre sérico $55 \mathrm{ug} / \mathrm{dL}$; cobre urinário 505 ug/24h: ultra-sonografia de abdome: figado de dimensōes discretzmente reduzidas, contornns regulares e ecotextura grosseira, e baço de dimensões levemente aumentadas; das enzimas hepáticas apenas a aspartato-gama-aminotransferase estava ligeiramente aumentada; TC normal. A paciente foi tratada com D-penicilamina (1 g/dia) e, um ano após o início do tratamento, o exame neurológico era normal, porém ainda apresentava anel de Kayser-Fleischer. Os demais familiares são assintomáticos e não apresentam anormalidades quanto aos niveis de ceruloplasmina e cobre sérico, sendo que, em todos, a pesquisa do anel de Kayser-Fleischer foi negativa.

\section{COMENTÁRIOS}

Os casos em questão exemplificam a ocorrência de duas afecções extrapiramidais, a DW e quadro distônico não wilsoniano, na mesma família. Os exames do caso 1 mostraram que esse paciente não era um homozigoto para $\mathrm{DW}$, já que o nivel de ceruloplasmina estava pouco abaixo do normal, as concentrações de cobre sérico e urinário eram normais e o cobre hepático situava-se em faixa acima do normal, porém abaixo dos valores habitualmente encontrados em pacientes wilsonianos, nos quais situam-se acima de $250 \mathrm{ug} / \mathrm{g}$ de peso seco ${ }^{8}$. Da mesma forma, a ausência do anel de Kayser-Fleischer e o longo tempo de evolução sem tratamento específico, descartaram definitivamente a DW. Por outro lado, a taxa de ceruloplasmina e o teor de cobre tecidual hepático sugerem tratar-se de um heterozigoto para DW.

A presença de reação inflamatória crônica de tipo granulomatoso demonstrada ao exame histológico do fígado é intrigante. Não se trata de alteração habitualmente encontrada na DW; esse tipo de lesão foi descrito em casos de intoxicação exógena por fungicidas contendo sulfato de cobre 6 . Doenças de natureza infecciosa como a tuberculose, sarcoidose ou mesmo viroses e micoses são causas comuns de reação granulomatosa no fígado mas, no presente caso, a ausência de manifestações clinicas sugestivas e de alterações bioquímicas, sorológicas e radiológicas compatíveis afastam essas possibilidades. A utilização de drogas durante longo tempo como tentativa de conirolar o quadro neurológico poderia estar relacionada com o processo granulomatoso. A detecção de granuloma hepático é relativamente frequiente e em determinadas casuísticas atinge a cifra de $9 \%$ das biópsias hepáticas 1 , sendo que 6 a $36 \%$ desses casos são de etiologia indeterminada 5 .

Outro aspecto ainda desconhecido nos heterozigotos para DW é o comportamento histológico do tecido hepático, a longo prazo, frente a depósitos de cobre aumentados. Poderiam surgir anormalidades semelhantes às observadas no presente caso?

Os registros de literatura referentes a casos semelhantes ao descrito sāo raros 2-4,7. Parker 4, em 1985, descreveu uma família na qual, em 5 gerações, 22 membros apresentavam distúrbios do movimento, na sua maioria do tipo distônico e, com menor freqüência, coréia. Em vários casos, associavam-se aos distúrbios motores manifestações de deterioração mental. Entre os 22 casos nessa família, estavam presentes dois pacientes com quadro clínico, anormalidades bioquímicas e histologia 
hepática compativeis a DW. Nos 20 outros casos năo havia anormalidades do metabolismo de cobre. No relato de Quinn e Marsden 7, são apresentados três pacientes com distúrbios do movimento e anormalidades do metabolismo do cobre compatíveis a heterozigose para DW. O primeiro desses casos apresentava, do mesmo modo que o caso 1, história familiar de $\mathrm{DW}$, porém o quadro era de tipo rígido-acinético. Pall e col. ${ }^{3}$, em descrição recente, relataram mais um caso de síndrome extrapiramidal associada a anormalidades do metabolismo do cobre sugestivas de heterozigose para DW.

Que mecanismos etiopatogênicos poderiam determinar o aparecimento dessa estranha associação? Para Quinn e Marsden 7, a herança de um gene para DW não é suficiente para determinar as complicações neurológicas da doença, mas pode sê-lo, caso se associe à herança de outro gene relacionado a doença neurológica. Por outro lado, Pall e col.3 aventam a possibilidade de que a deficiência concomitante de ceruloplasmina e glutation possa permitir a ação oxidante exercida por ions metálicos. A ceruloplasmina é o principal antioxidante do plasma humano e o glutation tem o mesmo papel a nivel intracelular. Para esses autores, portanto, a leve deficiência de ceruloplasmina em heterozigotos habitualmente não se reflete em falência dos sistemas anti-oxidantes mas, se associada à carência de glutation, pode proporcionar condições para o dano celular. Segundo Heckmann e Saffer $\mathbf{2}$, uma forma peculiar de erro metabólico poderia limitar o efeito tóxico do cobre ao sistema nervoso central. vesse modo, o distúrbio do metabolismo do cobre seria insuficiente para causar lesôes hepáticas graves como as observadas na DW mas condicionaria o aparecimento de manifestações neurológicas.

A literatura a respeito do tema é restrita, mas abre novo aspecto no enfoque da DW e coloca como questão básica a vulnerabilidade às doenças neurológicas dos heterozigotos para essa moléstia, até pouco tempo atrás considerados como pessoas normais. Por fim, deve-se enfatizar que, diante de síndromes extrapiramidais de etiologia desconhecida, a possibilidade de heterozigose para a DW como fator predisponente deve ser considerada.

\section{REFERENCIAS}

1. Berck JE, Cohen M. - Hepatic granulomas. In Berck JE (ed): Bockus Gastroenterology. Saunders, Philadelphia, 1985, vol 5, pg 3189.

2. Heckmann J, Saffer D - Abnormal copper metabolism: another «non-wilson's» case. Neurology 38:1493, 1988.

3. Pall HS, William AC, Blake DR, Winyard P, Chirico S, Brailsford $\mathbf{S}-$ Movement disorder associated with abnormal copper metabolism and decreased blood anti-oxidants. $J$ Neurol Neurasurg Psychiat 50:1234, 1987.

4. Parker N - Hereditary whispening dysphonia. J Neurol Neurosurg Psychiat 48:218, 1985.

5. Penchas S, Ligumski M. Eliakim $M-$ Idiopathic granulomatous hepatitis with prolonged course effect of corticosteroid therapy. Digestion 17:46, 1978.

6. Pimentel JC, Menezes AP — Liver disease in vineyard sprayers. Gastroenterology 72:275, 1978.

7. Quinn NP, Marsden CD - Coincidence of Wilson's disease with other movement disorders in the same family. I Neurol Neurosurg Psychiat 49:221, 1986.

8. Scheinberg IH, Sternlieb I - Wilson's Disease. Saunders, Philadelphia, 1984, pg 114. 